\title{
Use of an ear oximeter to assess lung function
}

\author{
REIAH AL-DULYMI and R. HAINSWORTH \\ Cardiovascular Unit, Department of Physiology, University of Leeds
}

\begin{abstract}
Al-Dulymi, R. and Hainsworth, R. (1975). Thorax, 30, 566-568. Use of an ear oximeter to assess lung function. Values of arterial oxygen saturation were estimated using an ear oximeter while subjects breathed a mixture of $15 \%$ oxygen in nitrogen. Results obtained from patients with lung disease were clearly separated from results obtained from normal subjects, and the lowering of saturation was related to the clinical severity of the disease. Patients with low oximeter readings with $15 \%$ oxygen also had low levels of arterial oxygen tension during exercise.
\end{abstract}

Probably the most accurate method for assessing overall lung function is to determine the arterial blood gas tensions during exercise. However, this method is time consuming, involves arterial catheterization, and requires equipment for blood gas analysis. We have developed a simple method for assessing lung function by reducing the oxygen content of the inspired air and measuring the effect on haemoglobin saturation using an ear oximeter.

\section{METHODS}

There were 21 normal subjects, male and female aged $16-68$, with no history of pulmonary or cardiac disease and 52 patients undergoing routine pulmonary function studies. The diagnoses were chronic airways obstruction (33), asbestosis (4), sarcoidosis (3), fibrosing alveolitis (3), and pneumoconiosis (1). Eight patients were found to have no abnormality of lung function as assessed by standard tests (lung volumes, expiratory flow rates, and blood gas tensions during exercise). The clinical diagnoses in these patients were bird fancier's disease' (4), sarcoidosis (2), silicosis (1), and 'breathlessness' (1). The blood gases and $\mathrm{pH}^{\text {. }}$ and forced expired volume/forced vital capacity ratios in these groups are listed in the Table.

A vasodilator cream was rubbed on the uppero part of the subjects' ears and the subjects wereo seated in a comfortable high-backed chair with å V-shaped head support to which the oximeter ear $\overrightarrow{\vec{B}}$ piece was clamped. The oximeter (Atlas Uni-3 versal, type E45B) was set up by adjusting one point on the scale when the subject breathed? $100 \%$ oxygen and another set point when the ear was made ischaemic by compressing it be-음 tween the light source and the detector. Used in $\times$ this way arterial haemoglobin saturations couldo be predicted from a regression line with an ac curacy of $\pm 2.9 \%$ ( 2 standard deviations) foro haemoglobin saturations above $65 \%$.

A gas mixture containing $15 \%$ oxygen in nitro음 gen was transferred from a cylinder to a 1201 . spirometer which was always well flushed out withㅡㅡㄹ

T A B L E

BLOOD GASES, pH, AND FEV $_{2}$ FVC RATIOS IN THE THREE GROUPS OF PATIENTS: MEANS \pm SD AT REST AND ONC

\begin{tabular}{|c|c|c|c|c|c|c|}
\hline & \multicolumn{2}{|c|}{$\begin{array}{l}\text { Chronic Airways } \\
\text { Obstruction (33) }\end{array}$} & \multicolumn{2}{|c|}{$\begin{array}{l}\text { Other Lung } \\
\text { Disease (11) }\end{array}$} & \multicolumn{2}{|c|}{ 'Normal Patients' (8) } \\
\hline & Rest & Exercise & Rest & Exercise & Rest & Exercise \\
\hline $\begin{array}{l}\mathrm{PaO}_{2}(\mathrm{mmHg}) \\
\mathrm{PaCO}_{2}(\mathrm{mmHg}) \\
\mathrm{pHa} \\
\mathrm{FEV}_{1} / \mathrm{FVC} \%\end{array}$ & $\begin{array}{r}76 \cdot 9 \\
\pm 13 \cdot 1 \\
38 \cdot 4 \\
+4 \cdot 7 \\
7 \cdot 39 \\
\pm \quad 0.07 \\
57 \\
\pm \quad 5.6\end{array}$ & $\begin{array}{c}65 \cdot 0 \\
+14 \cdot 1 \\
42 \cdot 4 \\
+7 \cdot 7 \\
7 \cdot 37 \\
\pm 0.05\end{array}$ & $\begin{array}{c}79 \cdot 4 \\
+11 \cdot 7 \\
37 \cdot 8 \\
+3 \cdot 3 \\
7 \cdot 41 \\
+0.04 \\
81 \\
\pm 8 \cdot 0\end{array}$ & $\begin{array}{r}59.9 \\
+14.1 \\
40.0 \\
+5.8 \\
+7.38 \\
+0.05\end{array}$ & $\begin{array}{c}97 \cdot 5 \\
\pm \quad 8 \cdot 7 \\
37 \cdot 5 \\
+3 \cdot 7 \\
7 \cdot 42 \\
+0 \cdot 03 \\
81 \\
+5 \cdot 0\end{array}$ & $\begin{array}{r}95.9 \\
\pm \quad 5.3 \\
38.0 \\
+2.0 \\
7.41 \\
\pm \quad 0.05\end{array}$ \\
\hline
\end{tabular}


gas before being filled. The subjects were fitted with nose clips and, using a two-way Douglas valve, breathed in from the spirometer and out into the room. Readings were first taken from the oximeter while the patient was breathing room air and again after breathing $15 \%$ oxygen in nitrogen for 4-5 minutes.

All the patients underwent a standard exercise test. They stepped on and off a $30 \mathrm{~cm}$ step 20-30 times per minute. Arterial blood was withdrawn through a brachial artery catheter during the fifth minute of exercise and analysed for oxygen tension with an oxygen electrode (Electronic Instruments Ltd).

\section{RESULTS}

HAEMOGLOBIN SATURATION (USING EAR OXIMETER) WHEN BREATHING ROOM AIR AND $15 \%$ OXYGEN IN NITROGEN In the normal subjects the average estimated haemoglobin saturation when breathing room air and $15 \%$ oxygen were $96.6 \%$ (SD \pm 0.90 ; range $94-97)$ and $93 \cdot 1 \%$ (SD $\pm 1 \cdot 62$; range $88-96$ ) respectively.

In the eight patients with normal results from conventional lung function tests ('normal patients') the estimated saturations with room air and $15 \%$ oxygen were $93.8 \%$ (SD \pm 3.54 ; range $88-98$ ) and $88 \cdot 2 \%$ (SD $\pm 1 \cdot 34$; range $86-90$ ).

The estimated haemoglobin saturation in all other patients when breathing room air (range $68 \%-96 \%$ ) was significantly different from both the normal groups $(P<0.001)$. However, there was considerable overlap of individual results. On the other hand, the values obtained in patients breathing $15 \%$ oxygen (range $58 \%-88 \%$ ) showed no overlap at all with the control group and only one overlap with the 'normal patients' group.

COMPARISON OF RESULTS OF OXIMETER TEST WITH RESULTS OF EXERCISE TEST The results of estimated oxygen saturation when breathing $15 \%$ oxygen have been plotted against the results, in the same subjects, of the arterial blood oxygen tensions breathing room air during the fifth minute of exercise (Figure). There is a highly significant correlation between these results $(r=0.80$, $P<0.001$ ). The points have been divided into nine rectangles by drawing lines through the points corresponding to $86 \%$ and $76 \%$ saturation and $80 \mathrm{mmHg}$ and $65 \mathrm{mmHg}$ tensions. The points in the upper right rectangle were within normal limits by both tests. The points in the middle rectangle were moderately abnormal and those in the lower left rectangle severely abnormal by both

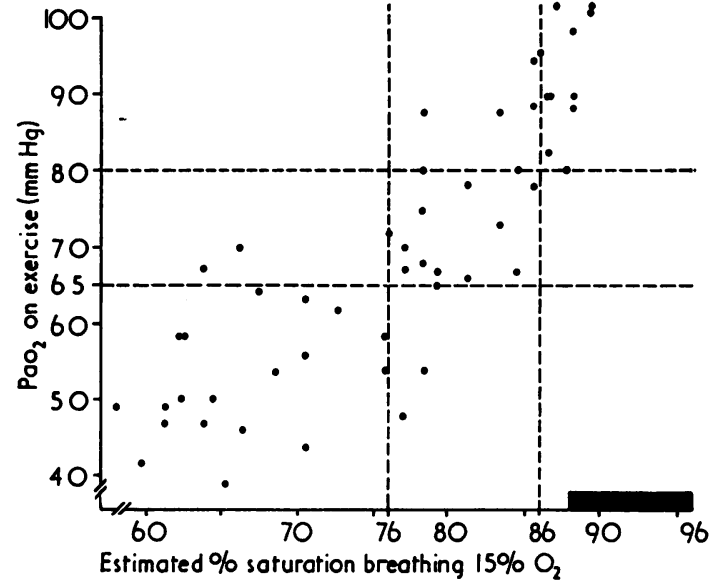

FIGURE Comparison of oxygen tension of blood taken during fifth minute of exercise with haemoglobin saturation on breathing $15 \%$ oxygen. Saturations estimated using ear oximeter and regression equation. Range $88-96 \%$ saturation obtained in control subjects (no arterial tensions). Horizontal and vertical interrupted lines are arbitrary limits of moderately severe and severe results.

tests. Four patients were moderately abnormal by the oximeter test and normal by the exercise test and four were moderately abnormal by one test and severely abnormal by the other. However, no patients were normal by one test and severely abnormal by the other. There was good agreement in 44 out of 52 patients and no failure of the oximeter test to predict patients who had low oxygen tensions on exercise. The eight patients in whom there was not good agreement reflect the statistical scatter of the results; four had bronchitis and four had other diseases associated with hypoxaemia.

\section{DISCUSSION}

The sensitivity of this test of lung function is achieved because of the shape of the oxygen dissociation curve for haemoglobin. Because the top part of the curve is flat, measurements of saturation when breathing room air are much less sensitive as an indicator of impaired lung function than are measurements of oxygen tension. However, when the subject breathes $15 \%$ oxygen, if alveolar $\mathrm{CO}_{2}$ tension remains normal, alveolar oxygen tension should drop to about $70 \mathrm{mmHg}$. If the difference between alveolar and arterial oxygen tensions is less than $10 \mathrm{mmHg}$, arterial oxygen tension would be greater than $60 \mathrm{mmHg}$ and haemoglobin saturation would be 
greater than $90 \%$. Below $60 \mathrm{mmHg}$ the dissociation curve becomes steeper and saturation falls more sharply. Arterial oxygen tension would fall below $60 \mathrm{mmHg}$ if the alveolar to arterial difference in oxygen tension was abnormally large or if the carbon dioxide tension was abnormally high. We measured $\mathrm{Paco}_{2}$ in 25 patients breathing $15 \%$ oxygen and found no significant change from the values obtained during air breathing (values were $38.4 \mathrm{mmHg}, \mathrm{SD} \pm 4.9$ and $38.8 \mathrm{mmHg}, \mathrm{SD} \pm 4.4$ breathing $15 \% \mathrm{O}_{2}$ and air respectively).

In order to be useful the test of lung function must clearly separate the results from patients with lung diseases from those from normal subjects. There should be no patients with normal results, there should be no normal subjects with abnormal results, and the results of the test should correlate with the severity of the disease. The results of the estimated saturation during $15 \%$ oxygen breathing satisfy these criteria. The results correlated well with the results of the standard exercise test. The results of the oximeter test never failed to detect patients with lung disease. There were no normal subjects with saturation below $88 \%$ and there were no patients with any of the lung diseases studied who had a saturation greater than $88 \%$. It is interesting to note that the eight patients who were found to have no abnormality to routine tests of lung function did have a significantly lower saturation on breathing $15 \%$ oxygen than the control group.
It is possible, therefore, that our test is more sene sitive to minor disorders than the conventiona $\bar{\Phi}$ tests.

Our test of breathing $15 \%$ oxygen has advan $\mathbb{8}$ tages over a rebreathing method described by Lalp Gebbie, and Campbell (1966) because the inspired oxygen mixture is accurately known in our method. This means that normal values can bह predicted accurately and there is less risk of severe hypoxia than when the alveolar oxygen is continuously falling.

Ear oximetry combined with breathing slightly hypoxic mixtures has been shown to be of valuej in detecting impaired lung function. While it is not suggested that it can replace arterial bloof gas analyses for the accurate assessment of lung function, oximetry is easy, safe, and, because it if non-invasive, readily repeatable. Ear oximetry used in this way could have a useful rôle in the assessment of lung function, both as a screening test and in follow-up studies.

\section{REFERENCE}

Lal, S., Gebbie, T., and Campbell, E. J. M. (1966) Simple method for improving the value of oximetry in the study of pulmonary oxygerf uptake. Thorax, 21, 50.

Requests for reprints to: Dr. R. Hainsworth, Cardio vascular Unit, Department of Physiology, The Univer sity, Leeds LS2 9JT. 